Editor's Note: These short, critical reviews of recent papers in the Journal, written exclusively by graduate students or postdoctoral fellows, are intended to summarize the important findings of the paper and provide additional insight and commentary. For more information on the format and purpose of the Journal Club, please see http://www.jneurosci.org/misc/ifa_features.shtml.

\title{
Tracking an Invisible Target Reveals Spatial Tuning of Neurons in the Rostral Superior Colliculus Is Not Dependent on Visual Stimuli
}

\author{
Marion R. Van Horn \\ Department of Physiology, McIntyre Medical Research Building, McGill University, Montreal, Quebec, Canada H3G 1Y6 \\ Review of Hafed et al. (http://www.jneurosci.org/cgi/content/full/28/32/8124) and Hafed and Krauzlis \\ (http://www.jneurosci.org/cgi/content/full/28/38/9426)
}

The superior colliculus (SC) plays an essential role in the sensory-motor mechanisms that underlie saccadic eye movements. The superficial layers of the SC receive visual information from the retina and striate cortex, and the intermediate and deep layers send outputs to motor centers in the brainstem that are responsible for driving saccades. Microstimulation and single-unit recordings have shown that neurons in the intermediate and deep layers of the SC form an orderly motor map where larger saccades are represented more caudally than smaller saccades (Robinson, 1972; Wurtz and Goldberg, 1972). More specifically, when gaze is shifted to an object of interest, neural activity progressively moves across the SC indicating the distance between the current eye position and the final goal (i.e., position error) (Munoz and Guitton, 1991; Munoz and Wurtz, 1993a; Bergeron et al., 2003). At the rostral tip of the SC, neurons represent small position errors

Received 0ct. 21, 2008; revised Dec. 11, 2008; accepted Dec. 11, 2008. This work was supported by the Natural Science and Engineering Research Council of Canada and the Fonds de la Recherche en Santé du Québec. I thank my supervisor, Dr. Kathleen E. Cullen, for her guidance and for providing insightful comments on this manuscript. I also thank Jessica Brooks for critically reading this manuscript.

Correspondence should be addressed to Marion R. Van Horn, Department of Physiology, McGill University, Room 1218, 3655 Promenade Sir William Osler, Montreal, Quebec, Canada H3G 1Y6. E-mail: marion.van_horn@mail.mcgill.ca.

D0I:10.1523/JNEUROSCI.5073-08.2009

Copyright $\odot$ 2009 Society for Neuroscience $\quad$ 0270-6474/09/290589-02\$15.00/0 for multiple eye movements including very small saccades, smooth pursuit, and fixation (Krauzlis et al., 1997; Bergeron and Guitton, 2000; Choi and Guitton, 2006). Although these later signals would be appropriate for signifying that a goal is being reached, there is controversy as to whether neurons in the rostral SC indicate a goal has been achieved. In other words, does the activity in the SC ever specify "zero" error?

Recent experiments by Hafed and Krauzlis (2008) and Hafed et al. (2008) provide new insight into the functional role of the rostral SC. Specifically, Hafed and Krauzlis (2008) provide strong evidence that activity in the SC reflects position errors during pursuit eye movements even when no visual stimulus is present, per se. Tracking an object without a visual stimulus is unique insofar as we generally consider smooth pursuit as a type of eye movement that requires a visual signal. Unlike saccadic eye movements, smooth pursuit cannot occur without an appropriate stimulus. Hafed and Krauzlis (2008), therefore, designed a task where a visual stimulus could be dissociated from the motor command. Two bars, which moved together sinusoidally, were presented on opposite sides of a screen, and monkeys were rewarded for following the midpoint between the two moving bars. In a sense, monkeys were trained to track an "invisible" target. Once the monkeys were trained to track invisible targets, the authors recorded individual neurons in the SC (Hafed and Krauzlis, 2008).

Hafed and Krauzlis (2008) found that the discharge of neurons in the rostral SC was modulated during the pursuit of an invisible target, whereas neurons in the caudal SC were relatively unresponsive. The modulations of example rostral SC neurons are illustrated in Hafed and Krauzlis (2008), their Figure 2 (http:// www.jneurosci.org/cgi/content/full/28/ 38/9426/F2) and Hafed et al. (2008), their Figure 2 (http://www.jneurosci.org/cgi/ content/full/28/32/8124/F2). Notably, contralateral pursuit resulted in an increase in the neuron's neural discharge, and ipsilateral pursuit resulted in a decrease in discharge. The results of Hafed and Krauzlis (2008) extend two previous findings.

First, the results are consistent with data that have shown that if a target is momentarily turned off when a monkey is actively fixating (for example, during a blink paradigm), neurons in the rostral SC continue to discharge. This demonstrates that the SC is not dependent on visual stimulation (Munoz and Wurtz, 1993a). Second, Hafed and Krauzlis (2008) confirm that neurons in the rostral SC are modulated during pursuit (Krauzlis et al., 1997; Basso et al., 2000) such that the spatial tuning estimated during pursuit is comparable with that estimated 
spatial tuning during small saccades (Krauzlis et al., 1997). Notably, spatial tuning was calculated in terms of "retinotopic goal locations." This was calculated by determining the difference in distance between the current eye position and the inferred goal location. The novelty in Hafed and Krauzlis's (2008) study was that the authors revealed that the representation of the small mismatches is reliable even when the final goal location is not visual.

To further investigate the functional significance of their single unit findings, Hafed et al. (2008) evaluated performance in the invisible tracking task after the SC had been temporarily inactivated with microinjections of muscimol at different rostral/caudal locations throughout the SC (Hafed et al., 2008). Interestingly, inactivation at the rostral section of the SC, which represents the central portion of the topographical SC map, resulted in a systematic offset in eye position. However, no motor deficits (i.e., saccades, pursuit, or fixation) were reported [Hafed et al. (2008), their Fig. 3 (http://www. jneurosci.org/cgi/content/full/28/32/ $8124 / F 3)]$. In other words, the monkey's ability to estimate the midpoint was impaired. Specifically, the offset was directed away from the estimated position encoded by the inactivated region of the SC. For example, silencing neurons that encoded right goal locations resulted in a bias to the left.

Together, the results of Hafed and Krauzlis (2008) and Hafed et al. (2008) provide further evidence that the SC contains a continuum of neurons that encode mismatches between the eye and the location of the final goal, rather than specific saccade vectors. What remains a topic of debate is what happens at the rostral tip of the SC. On the one hand, previous studies have defined neurons in the rostral SC as "fixation" neurons, because they are activated once the eye has reached a desired target (i.e., when error reaches zero) (Bergeron and Guitton, 2000; Choi and Guitton, 2006). However, it has been proposed that these neurons are not encoding absolute zero error but are rather more finely tuned to very small errors (Krauzlis et al., 1997; Hafed and Krauzlis, 2008). The data presented by Hafed and Krauzlis
(2008) and Hafed et al. (2008) support the latter; classically defined fixation neurons in the rostral SC are maximally activated when the eye is very close to the goal (i.e., small errors) but not when the eye has reached the final goal location.

Despite these new data, questions regarding the discrepancy in the interpretation of the functional role of the rostral SC neurons remain. Have previous studies that described rostral SC neurons as encoding zero error failed to describe gaze errors accurately? Alternatively, could the proposed continuum of neurons encoding small errors extend to zero error?

Unfortunately, because of differences in the identification and classification of rostral SC neurons, it is difficult to determine if Hafed and Krauzlis (2008) and the authors of previous studies are describing the same class of neurons. Hafed et al. (2008) identified sites for inactivation in the rostral SC by evoking small saccades using mircostimulation, whereas previous microstimulation of the rostral SC resulted in cessation or interruption of saccades (Munoz and Wurtz, 1993b; Chaturvedi and Van Gisbergen, 2000).

Additionally, an important characteristic of the neurons described by Hafed and Krauzlis (2008) is that they were tuned for very small errors occurring during saccades and smooth pursuit. Previous studies, however, have shown that not all neurons in the rostral SC discharge for small saccades. For example, Munoz and Wurtz reported that $35 \%$ of the neurons paused for saccades in all directions. Rostral SC neurons have also not always been described during equivalent behavioral tasks. Choi and Guitton (2006), for instance, did not evaluate the responses of rostral SC during pursuit or saccades that were less than five degrees. Consequently, some discrepancy in the results could be the result of recording and inactivating a slightly different subset of neurons.

In summary, Hafed and Krauzlis (2008) have confirmed that neurons in the rostral SC, which could be classified as fixation neurons, are tuned to small errors that occur during both saccades and smooth pursuit. They have also demonstrated that spatial tuning is not dependent on a visual stimulus. These results emphasize the need to more clearly differ- entiate the subclass of neurons that exist in the rostral SC. Determining if neurons that share many similar features, but are not completely identical, exist in the rostral SC could be crucial for understanding whether the data presented by Hafed and Krauzlis (2008) are mutually exclusive to the proposal that the SC contains a continuum of neurons that encode gaze error, which extends all the way to zero.

\section{References}

Basso MA, Krauzlis RJ, Wurtz RH (2000) Activation and inactivation of rostral superior colliculus neurons during smooth-pursuit eye movements in monkeys. J Neurophysiol 84:892-908.

Bergeron A, Guitton D (2000) Fixation neurons in the superior colliculus encode distance between current and desired gaze positions. Nat Neurosci 3:932-939.

Bergeron A, Matsuo S, Guitton D (2003) Superior colliculus encodes distance to target, not saccade amplitude, in multi-step gaze shifts. Nat Neurosci 6:404-413.

Chaturvedi V, Van Gisbergen JA (2000) Stimulation in the rostral pole of monkey superior colliculus: effects on vergence eye movements. Exp Brain Res 132:72-78.

Choi W, Guitton D (2006) Discharge characteristics of saccade-related neurons in primate superior colliculus during head-perturbed gaze shifts. Neuron 50:491-505.

Hafed ZM, Krauzlis RJ (2008) Goal representations dominate superior colliculus activity during extrafoveal tracking. J Neurosci 28:9426-9439.

Hafed ZM, Goffart L, Krauzlis RJ (2008) Superior colliculus inactivation causes stable offsets in eye position during tracking. J Neurosci 28:8124-8137.

Krauzlis RJ, Basso MA, Wurtz RH (1997) Shared motor error for multiple eye movements. Science 276:1693-1695.

Munoz DP, Guitton D (1991) Control of orienting gaze shifts by the tectoreticulospinal system in the head-free cat. II. Sustained discharges during motor preparation and fixation. J Neurophysiol 66:1624-1641.

Munoz DP, Wurtz RH (1993a) Fixation cells in monkey superior colliculus. I. Characteristics of cell discharge. J Neurophysiol 70:559-575.

Munoz DP, Wurtz RH (1993b) Fixation cells in monkey superior colliculus. II. Reversible activation and deactivation. J Neurophysiol 70:576-589.

Robinson DA (1972) Eye movements evoked by collicular stimulation in the alert monkey. Vision Res 12:1795-1808.

Wurtz RH, Goldberg ME (1972) Activity of superior colliculus in behaving monkey. 3. Cells discharging before eye movements. J Neurophysiol 35:575-586. 